\title{
Resources for Instructors of Capstone Courses in Computing
}

Report of ITiCSE 2001 Working Group 3

Tony Clear, WG Co-Chair

Auckland University of Technology

Auckland, NZ

tony.clear@aut.ac.nz

Frank H. Young, WG Co-Chair Rose-Hulman Institute of Technology

Terre Haute, IN 47801

frank.h.young@rose-hulman.edu
Michael Goldweber

Xavier University

Cincinnati, OH 45207

mikeyg@cerebro.xu.edu

Paul M. Leidig

Grand Valley State University

Allendale, MI 49401

leidig@gvsu.edu

Kirk Scott

University of Alaska Anchorage

Anchorage, AK 99507

afkas@uaa.alaska.edu 


\section{Abstract}

Most computing programs now have some form of integrative or capstone course in which students undertake a significant project under supervision. There are many different models for such courses and conducting these courses is a complex task. This report is intended to assist instructors of capstone courses, particularly those new to the model of teaching and learning inherent in the capstone course.

This paper discusses important issues that must be addressed when conducting capstone courses. These issues are addressed through a series of questions, with answers reflecting the way that different institutions have chosen to handle them, and commentary on the impact of these different choices. These questions include: Goals of the Course; Characteristics of Projects; Project Deliverables; Sponsors; Teams; Prerequisites and Preparation; Grading and Assessment; Administration and Supervision; and Reflection, Analysis and Review.

Subsequently we present information about the companion Web site, intended as an active repository of best practice for instructors of capstone projects. The Web site will have examples of information about capstone courses and materials used by instructors. Readers are invited to contribute content to this site. The paper concludes with a bibliography of additional reference material and resources.

\section{Introduction and Organization of Paper}

Most computing curricula have a special course, usually taken during part of the final year, that is considered a "capstone" course. This course is required of all students and is supposed to provide a culminating and integrative educational experience.

The capstone course places unique demands on students and requires special forethought on the part of the instructor. Content coverage may be significantly de-emphasized in favor of a more process-oriented and more integrative learning experience. Students may have less supervision and the course may have less structure. A greater "perfection of product" may be demanded.

There is a broad range of projects and working arrangements suitable for capstone courses. Students may work individually on research-type projects or may work as part of a team developing a software artifact for an external sponsor. Regardless of the exact form of the project, there are a large number of questions and policies that must be settled, e.g., what are the allowed types of projects, how are such projects conceived, what is to be produced from the project. Success in the capstone course is often predicated on the degree of consideration given to these issues. Instructor and departmental/institutional answers to these questions tailor the capstone course to local goals and the local environment, defining the array of options and experiences that are open to students in the course.

Capstone courses may have commonalities with other courses in the curriculum, such as software engineering, or may diverge widely from them. Whatever the form of the capstone course, one of its unique characteristics is the balance that it strikes between product and process. Capstone courses usually involve completion of a finished product, e.g., research-type paper, formal presentation, software artifact, formal report. Yet at the same time their emphasis is on the methodology and process involved. This is not the paradox it seems. The focus of the capstone course is to impart experiential knowledge while bringing a major project to successful completion. This supports the integration of and reflection on the knowledge that students have gained during previous stages of their education.

There are unique, non-trivial demands placed on instructors and course coordinators of capstone courses. Many of these demands are related to the multiple, and often conflicting, roles instructors must fill. The instructor may need to assume concurrently the roles of project sponsor, mentor, research associate, evaluator, confidant, etc. It is important to observe that the relationship with the student changes as the role performed by the instructor changes. The various roles need to be carefully balanced in the interests of acting ethically and fairly, fostering independence of students, and achieving course goals. Above all the instructor is charged with a "duty of care" in the oversight of student work.

The ability to bring a significant project to successful completion through independent work or teamwork is the hallmark of a valued individual. Through the capstone course students have the opportunity to demonstrate to themselves and others that they are prepared for future challenges. The instructor has the duty of guiding this integrative, culminating experience, and will share in the satisfaction of a positive outcome.

Initially, the effort required to prepare for and keep up with students in the capstone course can appear overwhelming, especially for a new instructor. The number of important issues that must be addressed, policies that must be set, and questions that must be answered seems almost limitless. 
However, a reasonable amount of careful prior thought and preparation will solve many problems and prevent many surprises. This paper aims to help instructors through the maze of decisions so that they are less daunted by the course challenges and, as a result, are able to achieve better student outcomes. Various institutions have gained extensive experience in conducting capstone courses. Although materials may not transfer directly from one institution to another, this collective experience may prove helpful in developing or improving a capstone course at another institution.

In the rest of this paper we discuss important issues that must be addressed when conducting capstone courses. These issues are addressed through a series of questions with commentary on the impact of the question's answers. In some cases, the commentary is preceded by possible "answers," based upon the ways that various individuals and institutions have chosen to handle the question. These questions and answers are not intended to be definitive, strictly prioritized or exhaustive lists, but should cover many of the more important issues.

The questions are organized into categories as follows: Goals of the Course, Characteristics of Projects, Project Deliverables, Sponsors, Teams, Prerequisites and Preparation, Grading and Assessment, Administration and Supervision, Reflection, Analysis and Review. Following the discussion of issues we present information about our Web site with examples of materials used by instructors. The paper concludes with a bibliography of additional reference material and resources.

\section{Definition of Terms}

Many different terms are used when describing capstone projects and their implementation. Different cultures use different terms for identical concepts. The vast diversity among educational institutions (small, large, undergraduate only, graduate program, state supported, independent, selective admissions, open admissions, etc.) make it very difficult to communicate accurately using any one set of terms. In this paper we have used one possible set of terms. They are not the only ones that could be used. We leave to the reader the task of converting the terms used in this paper into the terms used in a given country or a specific institution. To help in that conversion, we describe here the terms used in this paper and give some idea of the range of possible interpretations of those terms.

- capstone course - a capstone course may include a project or "research-type" [14] experience. It may include relatively structured assignments, extremely openended assignments or student created assignments.
- project - we use the term project to designate the work required in the capstone course. Examples of such work include software development and research-type investigation.

- team - a student team may be only one student or may include several students or might even include a large number of students.

- sponsor - we use the word sponsor to designate the person or group for whom the work is ultimately performed. This may be a sponsor external to the university, a sponsor external to the department, a staff member different from the course instructor, etc. This term is synonymous with the term "client". In some models of the capstone course the sponsor may be internal to the department, perhaps the instructor who has designed the course

- instructor - we use the term instructor to designate the person who is charged with the task of supervising the course instruction. Alternative terms for this person include supervisor or mentor. Instructors may be members of the faculty, graduate students, or non-faculty professionals, depending on policies and practices at the institution.

- coordinator - we use the term coordinator to designate the person who provides overarching direction for the capstone course and is also responsible for leading a team of supervisors.

\section{Goals of the Course}

There are many important decisions that a department that offers a capstone course must make. Instructors involved in capstone courses are forced to decide upon an unusually large range of issues. However, before addressing these issues in more depth, it is important to pay careful attention to the top-level of decision making - the course goals.

\section{What are the goals of the course?}

- To prepare students for graduate studies.

- To prepare students for entry into the workplace.

- To develop student capability, confidence, and maturity.

- To allow for the integration of and reflection on previous knowledge.

- To provide the opportunity for a studentdirected investigation or research-type project.

- To provide a "programming in the large" experience. 
- To develop experience using professional practices in a teamwork setting.

- To model industrial practice regarding commercial software development, and effective sponsor relationships.

It is unlikely that any capstone course will have only one of these goals. Most likely the course goals will be a subset of the above items, with the individual items in the subset weighted in a unique way. Some institutions may even support multiple versions of the capstone course, each one of which has a different set of goals. For example, an institution may choose to have two capstone courses - one course involving software engineering practice with its primary goal developing professional practice in a teamwork environment and another course involving more research-type activities with its primary goal preparing students for graduate work. In every case, the goals of the course will have significant impact on all the other design decisions the course instructor will face.

When determining course goals the "product versus process" tension must be kept in mind. Product-oriented capstone courses focus on the completion of a given project - a primary deliverable. The student is evaluated on the robustness and quality of the delivered software. Process oriented capstone courses are less concerned with the product or the question of "does it work?" They focus on critical analysis and reflection upon the process used to develop the product.

\section{What is the role of the capstone course in the student's curriculum?}

A capstone course must be appropriate for the specific program or curriculum. This means that the instructor or course coordinator must design the course to take into account the previous courses, assignments, and experiences of the students. Therefore, it is appropriate to consider the following questions when designing a capstone course:

- Does the prior curriculum adequately support the capstone course?

- Do the goals of the capstone course drive the curriculum, or is the capstone course the natural culmination of the curriculum?

- Are there any special characteristics to the capstone course? If so, what are they?

- Are the students adequately informed about and prepared for any radically different student tasks and assessment in the capstone course?

- Is success in the capstone course predicated on a change in the existing instructor student relationship? If so, what and how?

\section{Characteristics of Projects}

What is an appropriate capstone project? Given a lucidly enumerated set of course goals it should then be possible to characterize appropriate and (possibly even more important) inappropriate capstone projects.

\section{What are potential characteristics of a capstone project?}

- Software development is required.

- Students must work in teams.

- $\quad$ Projects must be student selected.

- Projects must be treated as an employment related assignment.

- $\quad$ The project must be much more open-ended or ill defined than any other the student has undertaken.

- $\quad$ The project must involve understanding and maintaining an existing software entity.

- Oral presentations and/or papers must be important components of the experience.

- Team - sponsor interaction must be professional and realistic.

- Student reflection on the experience must be required.

- Project complexity must be significantly beyond what the students have experienced before.

- The project must deliver a quality finished product; one that is complete, polished, and maintainable.

- Students must learn some new computing topic (as opposed to gaining further experience in areas they have already been exposed to).

- The project must provide a research type experience.

- At least one theorem must be proved.

- The product of the capstone course must be publishable or marketable.

This list suggests the various dimensions that a given project might have. Depending on the choices made, other issues/questions arise.

For projects containing a software development component, what portion of the software lifecycle needs to be implemented? For projects that are integrative of previous knowledge, a proof of concept implementation may be sufficient. For "programming in the large" type experiences, limiting the project to the implementation phase may be appropriate. Finally, projects that model industrial practices may endeavor to apply the full software lifecycle (possibly omitting maintenance). 


\section{How does the nature of projects vary as student numbers grow?}

As the number of students studying in the program increases, the course may become considerably more structured. This may be done simply to manage the logistics involved with large numbers of students. In such an environment the capstone course may resemble more of a "taught" course. There may be many students working on one instructor-defined project, with a predetermined set of tasks and items to complete for formal assessment. [6]

\section{Who conceives (finds, suggests, creates) capstone projects?}

- $\quad$ Student team.

- Other students, e.g., students from other majors or courses of study, students in another course.

- Instructor.

- Course coordinator or department committee.

- $\quad$ Project sponsor internal to institution (e.g. Computing Center, Administrative units, Academic Departments, individual faculty).

- $\quad$ Project sponsor external to institution (e.g. non-profit, business)

- Institution coop/placement office.

Clearly the type of capstone project desired has a direct impact on the source of the project. For student-directed investigations, student conceived projects are often the most appropriate. For capstone projects intending to model industrial practice, externally sponsored projects may be most appropriate. While this affords the students a realistic experience, it also introduces significant complexity into project acquisition and supervision. External sponsors must be recruited, sponsor relationships must be managed, and the tensions that result from the differences in the goals of the educational institution and the sponsor must be continually monitored and resolved.

Some institutions may choose to model industrial practices using internal sponsors. Internal sponsorship may alleviate some of the logistical, legal, and ethical issues that arise with an external sponsor. However, the nature of the relationship between a student team and an internal sponsor may lack a certain quality of realism.

Instructor-conceived projects might result in reduced student motivation. Students may have had only instructor-conceived projects to date. Students, by contrast, may receive a significant boost in their motivation when they select their own project or receive a project from a sponsor.

The quality and success rate for capstone course projects will normally be higher than in regular courses. But even in capstone courses it is necessary to make sure that the project is not critical to the sponsor. To mitigate risks for both parties, a task that is on the critical path of a larger effort should be automatically rejected. Tasks that are critical for the sponsor place an undue focus on production of deliverables to agreed targets at agreed times. This will almost always be in conflict with the broader educational goals of the capstone course. There is also a serious risk of student exploitation.

\section{Who approves student proposed capstone projects? \\ - Instructor. \\ - Project sponsor. \\ - Course coordinator. \\ - Departmental committee. \\ - Joint department/industry committee. \\ - Peers (student committee). \\ - Examination committee (at time of final assessment).}

While some risks are acceptable, a vetting process ensures that the possibility of success for the student/team is appropriately high. It prevents impossible or overly difficult projects. It also ensures that the project is of sufficient complexity and scope to be intellectually and academically worthwhile. Sponsor-conceived projects present an additional burden on the instructor or course coordinator since negotiation typically is needed to adequately define/refine the project.

Each of the above alternatives has both pros and cons. Delayed approval can lead to students selecting intractable or trivial projects. Department committee or peer approval can be awkward or difficult to secure. Individual instructor approval may result in disparity in project complexity if opinions vary within the department. Finally, course coordinators can play an important role in creating more uniform standards.

It is important to consider both the number of students involved in the capstone course and the number of different instructors for the course. Solutions that work with populations of one size (of either students or instructors) may not work with different populations. In the face of large numbers of students, it may be decided to use instructor-selected projects or a conventionally organized (i.e., structured and taught) capstone course. In the face of large numbers of instructors, it may be decided to have a course coordinator.

\section{Project Deliverables}

Once the nature of the project has been determined, serious decisions must be made about the products that will be produced during the project. It is not enough to have required deliverables for the 
sponsor and the instructor. To consider only those deliverables that are given to others and/or assessed is almost always insufficient. Some products help the project team prepare other deliverables that will be assessed. Other products help the team maintain its ability to work as a team. It is vital that these types of products be regarded as important deliverables.

\section{What types of documents might be generated by a project?}

- Documentation of team processes and decision making for the purpose of internal management, e.g., schedules, testing plans.

- Documents produced for the instructor for educational or assessment purposes.

- Documentation of events for historical purposes, e.g., personal activity logs, meeting minutes.

- Documents recording agreements among the parties.

- Documents produced for formal submission to the project sponsor.

- Reflective documents, e.g., personal journals, evaluations.

The documents produced during a project can be classified according to their recipients - the team itself, the instructor, the department, or the sponsor. However, since the project is done with an academic purpose, all documents may be of interest to the instructor. Materials produced for group management may be used by the instructor to help manage the process. The instructor also needs to see all materials submitted to the sponsor. However, the sponsor need not necessarily see internal management documents or documents produced for academic purposes.

\section{When are documents produced?}

The important issue is insuring that all parties are in agreement as to the timing method that will be used. Schedules may be rigid or flexible but must be acceptable to all parties. Note that agreements need only involve those producing and examining the document and this group can be different for each document.

If the instructor's role is primarily to help the student, then documents might be submitted to the instructor for review before delivery to the sponsor. If the instructor's role is primarily evaluation of student performance, then materials might be submitted for review at the same time that they are submitted to the sponsor.

\section{What work process or methodology should be followed?}

- Completely instructor determined.

- Completely student determined.
- Negotiated, perhaps starting from an instructor determined template.

Given that the goals of the capstone course frequently include development of professional maturity, whether as a software development professional or as a researcher, it is advisable that an acceptable methodology or process be adopted and followed. What specific methodology or adaptation thereof is chosen is less important than the use of some formal process. There is educational value in letting students partially determine the process and requisite deliverables. However, requiring students to completely define the process to be used will severely limit the time available to apply the process that is selected.

\section{What specific work products are going to be required?}

- A bibliography of sources and resources for the project under consideration.

- A project statement or proposal outlining the problem to be solved and the methodologies to be used.

- Lists of ideas that might be relevant to a proposed research problem.

- A timeline dividing the project into its constituent parts, showing dates when these parts are to be completed and when associated deliverables might be presented.

- Design documents. These may differ depending on the type of project type. Examples include: UML models, database schemas, flowcharts or data flow diagrams, etc.

- Logs of administrative decisions, design changes, implementation decisions, etc.

- Descriptions of attempted solutions with explanations of failure and assessments of efforts.

- Individual participant logs and journals, possibly reflecting on process oriented issues.

- The software or system developed by the project.

- Software or system documentation.

- Users' and administrators' tutorials, manuals, etc.

- A final project report documenting all aspects of the project from inception to completion.

Since any enumeration of this sort can only be incomplete, this list is only a useful summary. Due to the distinctive nature of projects, and methodologies, each one will probably have a different set of deliverables, tailored to the specific circumstances. See [14, p. 64 and pp.104-106] for additional lists of possible deliverables. 
What project deliverables should be archived for future reference?

It is unlikely that all material is worth archiving. The key question is what purpose the archive is to serve. On the one hand, it could serve as a record of sponsors and the software/systems produced for them. On the other hand, it could serve as a guide for future students and an instructional resource for the department. Multimedia presentations of project proposals, progress reports, etc., might normally be regarded as ephemeral. However, good examples of such materials are worth saving for educational purposes.

\section{What editing will be done?}

Instructors must ensure that editing is done when appropriate and that time is allotted in the schedule for this activity. It may be advisable to require predeadline instructor review for certain crucial documents, particularly those that will be delivered to the sponsor. Peer reviews may also be helpful, both for the team being reviewed and the individuals doing the reviews.

\section{What presentations will be required? When will they be done?}

- Routine progress reports given at regularly scheduled intervals, e.g., weekly.

- Walk-throughs and reviews included in the project timeline in accordance with the methodology used.

- Presentations scheduled at the times that finished deliverables are given to the sponsor.

- Dry-run presentation of the final report to the instructor before the final presentation.

- Formal final report.

Presentations can be quite different in their effects. Some presentations convey the contents of an existing document. Others will result in the creation of a new document, e.g., minutes, lists of ideas. Presentations may also illuminate the process being used. The instructor needs to help the team make good use of presentations.

\section{What type of final presentation should be required?}

Seminar presentations are appropriate for research-type projects. There are many types of final presentations appropriate for software development projects, some written and some oral. Possible choices include a formal presentation to the sponsor and faculty, a formal report to the instructor, a demonstration to the sponsor and faculty, and an exposition-type presentation to the public (many projects at the same time).
It is important that the nature of the final presentation(s) be agreed upon in advance and that students receive clear information about the instructor's expectations. It is helpful to require students to view the presentations of others before their own presentations. It is also helpful to require a "dry-run" of important presentations so that students are able to identify problems before disaster strikes.

\section{Who should be invited to final presentations?}

This is a question of both the institutional norms and the availability of potential attendees. Some schools may not be able to draw appropriate audiences from outside the institution, or may only want people who are directly involved in the process to attend. There are important benefits from letting other students see the process.

Note that the final presentation is not necessarily the presentation of the final report to the sponsor. A final presentation that allows the team to present their accomplishments to the public can be a powerful motivator and can help improve quality and performance.

If part of the presentation process involves assessment and grading, there may have to be an open part of the presentation and another closed, or confidential, part of the presentation.

\section{Sponsors}

Many capstone courses are project-oriented and have a sponsor for the project that is done by the student, whether working individually or within a student team(s). Sponsors of software development projects are often external to the department. Research-type capstone experiences may also have external sponsors, such as a university research laboratory or center.

When there is no external sponsor for the project (e.g., all students or teams work on a single assigned project, an individual student works on a researchtype project), the department or the instructor may be considered the "default" sponsor and the instructor may have to assume the sponsorship role. All of the comments in this section may be applied to both the case of an external sponsor and the case of a “default” sponsor.

\section{Sponsor selection characteristics} and

What types of sponsors are going to be
used?
- There is no sponsor (the
instructor/department is the default
sponsor).


- The sponsor is internal to the university or an associated research facility.

- The sponsor is a non-profit/charitable organization.

- The sponsor is a business.

- The sponsors are a mixture of these possibilities.

Some capstone courses use a single project for all the teams or individuals. The instructor or the department normally creates this project assignment. Such a project will lack certain characteristics present in projects with other sponsorship. The relationship of the students with the sponsor will necessarily be different from a relationship with a third-party sponsor. In such a case, instructors must be careful to differentiate between their several roles.

Where teams or individuals have separate projects, an instructor may act both as sponsor and as mentor of a project. An instructor can be torn between the differing obligations of these two roles. The duties of sponsorship and the need for an arm'slength sponsorship relationship may at times conflict with the caring and mentoring duties of instruction. In general, it is wise to avoid this type of conflict.

Sponsors who are internal to the university usually will readily support the educational goals of the capstone course. Care must be taken to make these sponsors aware of the lack of continuing support and maintenance for products.

Charitable sponsors can provide excellent publicity for the department. However, quality (especially robustness) and ease of maintenance of the product are much more important for these sponsors. Any benefits of good publicity can be easily lost if an organization finds the product unusable after using it for a few months. If a system has been produced for a charitable organization, then the organization should not be put into the position of being forced to spend unavailable funds to overcome the deficiencies of student products.

Profit-making businesses can provide interesting projects. Care must be taken to ensure that businesses do not expect commercial quality products. Sponsors need to be aware of the goals of the institution and be willing to support them. The sponsor also needs to be willing to allocate appropriate time to the sponsorship. Businesses are sometimes willing to support the students doing the project by offering them employment.

\section{Are there restrictions on the location of the sponsors?}

- Permit only local sponsors.

- Permit sponsors located in the local region.

- Permit distant sponsors within the country.

- Permit international sponsors.
If there is support for electronic mail, telephone conference calling, and video conferencing, then there need be no restrictions on the location of the sponsor. However, financial considerations may require limitations on certain types of contact. Such limitations should be investigated before accepting (or recruiting) a sponsor.

When sponsors and students never meet face-toface there is great potential for misunderstandings to arise. Student teams who have distant sponsors will need assistance to make effective use of distance communication techniques. They will also need to be made aware of the costs of the technology being used.

Internationally-sponsored projects raise concerns about cultural differences. Some students may be effectively disqualified from participating on internationally-sponsored projects because of their limited cross-cultural experience.

\section{How are sponsors recruited?}

- By the instructor.

- By the department.

- By the students.

- By a combination of the above.

If the course instructor has sole responsibility for recruiting student projects then a change of instructor may have a serious impact on project quality, variety, and availability. Particularly in those environments where supervision is distributed among several instructors, it can be wise to have a centralized recruiting procedure. This also helps to establish valuable long-term relationships with sponsors.

Sources that departments have successfully used when recruiting project sponsors include:

- alumni.

- companies that recruit graduates for employment.

- companies that sponsor cooperative programs and internships for students.

- members of departmental advisory boards.

- newspaper advertisements.

- mailings to departmentally maintained contact list.

- $\quad$ flyers and information sheets distributed at local professional meetings.

\section{Relationships between students and sponsors}

Student projects involve shared risks. The students may or may not succeed in their studies. Sponsors may or may not receive something that is worth the time and effort they have expended. Both groups must recognize the legitimate interests and needs of the other. Both groups must actively work to manage the relationship and maintain consistent 
expectations of the amount and value of each other's contributions.

Note: If there is not a sponsor external to the department then the following should be interpreted as if the (default) sponsor is the instructor or the department.

\section{Can a sponsor dismiss a team for cause?}

There is no recourse if an external sponsor decides to stop sponsoring the project. Obviously, this situation should be prevented from ever arising. Techniques that can prevent such an event from occurring include:

- Clear articles of agreement accepted by sponsors and teams before start of project.

- Regular progress reports.

- Early identification of problems, perhaps by having an agreed upon method for project teams and sponsors to inform the instructor.

- Prompt preventative action by instructors when a team is acting irresponsibly.

- Prompt preventative action by instructors when a sponsor is acting irresponsibly.

- An established procedure for negotiating resolution of problems, perhaps involving the project coordinator or the department head.

\section{Can a team stop working for a sponsor in the middle of the capstone course?}

Such an event indicates that there has been inadequate attention to managing the team's relationship with the sponsor. The students should be well informed of the possible negative consequences to the department and the damage to the department's ongoing relationship with the sponsor. There may be situations where the welfare of the members of the student team requires severing a relationship with the sponsor. Giving all sponsors a document that establishes appropriate expectations for the project usually can prevent this. Rigid descriptions are not necessary. It is much better to clearly set the tone of the relationship and give examples of obviously inappropriate expectations and actions.

\section{How are team/sponsor conflicts resolved?}

Some conflict is inevitable because the parties have differing goals and interests. Conflict prevention is more important than conflict resolution. However, when there is a need for conflict resolution, the instructor is the first line of mediation.
Such mediation will be facilitated if there has been previous communication with sponsors about the procedures that will be used to resolve conflicts and what the expectations of the sponsors should be. As a last resort it may be necessary to involve the coordinator or department head.

\section{How are team/sponsor agreements documented?}

- Using prepared guidelines for all projects.

- Having formal signed and legally binding agreements.

- Creating periodic signed memos of understanding.

- Having informal verbal agreements.

- Using various types of agreements, depending on the nature of the issue.

Informal agreements often lay the groundwork for later disagreements. However, excessive formality can lead to indecision and inordinate delays. One common solution is to document formally all major decisions and get signed acceptances of all major milestone documents. Another solution is to prepare and use a set of departmental guidelines for capstone projects. These guidelines could describe how much of the documentation will be handled. Making general policy decisions in advance and communicating them to all parties will prevent many misunderstandings.

How are unforeseen sponsor disasters dealt with (e.g., inactive sponsor, transferred/ill/unavailable sponsor contact, merger/purchase/bankruptcy of sponsor)?

- The team starts a new project with a new sponsor.

- The team continues with the project using existing agreements.

- A pro tem sponsor is assigned from within the university.

- The answer depends on how much of the project has been completed.

The crucial issue here is the protection of the students. The instructor has a duty to care for the students and must assert appropriate authority when necessary. Flexibility is important. It may be difficult to determine a universally appropriate course of action in advance. However, whenever these situations arise, the instructor must be able and willing to act quickly and decisively to resolve the issue. 


\section{Communication between students and sponsors}

How and when should the team communicate with the sponsor?

- Face-to-face.

- Telephone conferencing.

- Video conferencing.

- Email.

- Whenever needed.

- According to a rigid schedule.

- A combination of the above.

Some institutions may wish to limit communication that is expensive or that involves additional costs to the department. If the sponsor is willing to absorb costs for telephone conferencing or video conferencing then there may be no problem.

There probably should be certain scheduled conferences between the team and the sponsor. Excessive numbers of meetings, excessive numbers of emails, excessive numbers of telephone calls, etc. will place an unreasonable burden on the sponsor. The instructor should take care to inform the team about the potential problems created by excessive communication. The team should also be informed about the multiple demands routinely placed on employees, demands that may often prevent immediate responses to questions.

"As needed" reviews can be attractive but may cause teams to delay more than they should. If scheduled reviews are arranged in advance then the procrastination problem is lessened. Overly rigid scheduling (e.g., no schedule changes allowed) may cause deterioration in the quality of the process.

\section{How are financial matters handled?}

Conduct of the capstone course under the wide range of potential scenarios available will inevitably raise a number of financial issues. These could involve such questions as coverage of additional costs, payments or contributions from sponsors, extra costs for specialized hardware or software, equipment or supplies, publication and copying costs, facilities for students and teams, travel and communication costs and a range of incidental expenses.

There are a number of policy issues that may need consideration here. In committing to capstone course or specific projects the resource dimensions should first be explicitly addressed. Clear policies in relation to sponsor contributions to project, university and departmental level resource commitments, and expectations of contribution from students who have already paid tuition fees are important. For instance if case tools, project management software or graphic tools are required, then ensuring that an adequate number of licenses are available to meet the needs of students and sufficient access to meet the demands of the course is an implicit requirement. If a tightly resource constrained capstone model is to be adopted then making sure the basic requirements are covered is a key consideration.

\section{What needs to be taken into account when considering financial support from sponsors?}

The question of payment for services and costs incurred can often be problematic. The answer to such questions depends upon the policy of the university towards such arrangements and whether they are regarded as instructional activities already covered by tuition fees or as semi-commercial activities. A number of options for sponsor support may be considered. For instance the department may agree to cover the costs of photocopying or student travel from a departmental account, a research project may provide specialized hardware and software resources such as a dedicated project server, an external sponsor may pay a fee for service or make a contribution of specific hardware or software to support capstone course work.

What payment arrangements should apply to projects? Should there be a flat fee for all sponsors? Who pays for what?

- No sponsor contribution, university pays full costs.

- Sponsor pays for extra costs incurred.

- Sponsor pays fee for services.

- Sponsor contributes necessary resources.

- Sponsor determines appropriate cash contribution to departmental or scholarship fund.

For taught capstone projects the costs should be borne by the department, but the university should provide dedicated or open access laboratory facilities suitably equipped to accommodate the intensive computer usage demanded during the capstone course. A range of minor expenses may arise for the university or the students in relation to projects, e.g., cost of travel to sponsor site, miscellaneous hardware and software items. It is advisable that the department reserve a limited budget (possibly funded by sponsor donations) to provide for such expenditures.

In those institutions where the capstone course is seen as offering shared rewards to internal/external sponsors and students, arrangements can normally be negotiated with sponsors to cover the marginal costs of the project such as extra hardware or specific 
software licenses. Sometimes arrangements may be negotiated to allow students to work on the sponsor's site for periods of time as required by the project.

Regarding capstone projects as semi-commercial ventures raises a huge risk of conflict of interest between the university as a commercial institution and as a place of learning. Under fee for service arrangements, clear agreements must be made between the university, the department and sponsor as to cost and risk apportioning, and remedies in the case of project delivery failure. There are very sound reasons not to operate in a commercial manner with capstone projects. As part of their learning experience students are inherently entitled to fail. The sanctions for instructors not rescuing failing projects should not be heightened by commercial pressure to have teams perform.

Where the university or department will incur significant costs through taking on the project, the project may become viable only if the project brings its own funding (e.g., an externally funded research project) or the sponsor is prepared to provide the extra resources to cover the costs involved.

A range of ways in which sponsors might contribute to capstone course support could be considered, such as cash donations to departmental or scholarship funds. Some of these could provide a means of establishing or reinforcing a continuing relationship with the department or university. A few suggestions are given in the sponsors' guidebook [8], which may be accessed, from the Web site associated with this paper.

\section{Legal, ethical and social issues with sponsors}

When the sponsor is external to the university there may be serious legal and ethical problems that must be resolved. Even when the sponsor is internal to the university, there are legal and ethical matters that must be carefully addressed before starting the project. There must be clear understandings concerning the ownership of the work, the nature of rewards, the degree of secrecy required, etc. Every project must include a review of the social impact of the resulting product.

\section{Who owns the resulting work products?}

- University.

- Sponsor.

- Student(s).

- Combination of the above.

- Designated party (e.g., student) retains ownership, but provides client/sponsor full rights of use, modification and further development.

- Designated party (e.g., student) retains ownership, but provides client/sponsor restricted rights of use (e.g., for non commercial, educational or research purposes, or provides rights to subcontract software maintenance and support to a third party).

- Open source or shareware type arrangements.

Some Universities have stringent intellectual property policies under which all rights to inventions and developments using university facilities and equipment will accrue to the university. The implications for student project work products should be clarified before the start of the course.

The university may have an open policy in relation to the archiving of student project reports, and may request that bound copies be provided to the department or library for future student or faculty reference. Where the department/lecturer is the default sponsor, it is unlikely that ownership of student work would be claimed.

Ownership issues need careful consideration when conducting work on behalf of an external sponsor. The copyright laws of many countries declare source code to constitute a literary work and thus ownership lies with the author of that work. By default therefore, the ownership of the software artifact that results from the project will lie with the student(s). If other arrangements are desired there needs to be a specific agreement made.

Often sponsors will wish to retain the rights to any software, proprietary ideas and documentation resulting from the project, and such rights should be clearly confirmed. Where a shared rights situation is acceptable, it is advisable to clarify what rights of use apply to the parties. If students wish to retain their work products for use in other contexts, they may be required to sign an agreement to refrain from using the products in any way that directly competes with the sponsor's products.

If the students wish to retain full rights to the software, but not continue to maintain the software as supplied to the sponsor, a specific provision allowing a third party to make modifications may be necessary. Spelling out clearly in advance responsibilities for ongoing maintenance of the application is strongly recommended. Students may otherwise have a sponsor for life!!

Where it is desired that the software be released into the public domain under a form of shareware or open source arrangement, the necessary procedures for confirming and supporting these arrangements (such as setting up a Web site and suitably hosting the software for download) may need to be made. 
Can students retain, reuse, and revise the design, documents and code they create?

The answer here will depend upon the ownership arrangements that have been agreed upon. Normally it is expected that students would retain these materials, and they can be useful supplements to portfolios when students apply for positions with prospective employers.

The sponsor may decline to allow students to retain certain parts of their work on grounds of commercial sensitivity, but sensible arrangements may normally be negotiated to enable students to keep copies for release under restricted circumstances.

Normally it is expected that students would retain these materials, and if they retain the rights of use or extension then they may freely modify or extend the software they have developed. The materials may form the basis for concepts for saleable items, or for the base of a small entrepreneurial business.

The sponsor may decline to allow students to retain their work on grounds of commercial sensitivity, in which case extension of the software would not be permissible. However, more generic ownership and reuse of the underlying ideas, techniques and concepts is a right that must remain with the students. In rare and extreme cases where significant commercial advantage or sensitivities may be involved, an embargo on the knowledge for a short and specified term may be considered, as has been applied occasionally to postgraduate dissertations.

\section{Can the school use the work products for instruction?}

The use of exemplars, e.g., previous project proposals, can be a very good mechanism for reinforcing appropriate techniques for presentation, style, standards, etc. For those cases where projects may vary widely and no significant advantage would accrue, this is a useful approach. To safeguard student's privacy rights, it is advisable to inform students that their work will potentially become part of a collective resource of examples to guide future students. It may, however, be inappropriate to include embarrassingly poor samples of student work in the pool of exemplar documents, even if the documents are "anonymous."

What are the effects of nondisclosure
agreements on the academic
environment? Should signing of
nondisclosure
permitted?

In the conduct of some models of capstone project courses students are expected to work in a manner befitting software development professionals. Thus concerns of commercial sensitivity are expected to be managed in a sensitive and careful manner. Many projects conducted on behalf of sponsors in commercial environments, require that students conduct themselves professionally and with care. In some cases students may sign confidentiality agreements, but this would not be the norm.

Confidentiality agreements should not be accepted if they prohibit the normal academic processes and sharing of information that would normally occur in the course of the projects as teams participate in project and quality reviews, and submit their projects to additional parties for approval. Likewise judicious exercise of the instructor's "duty of care" is necessary to ensure that students are not exposed to undue personal risk of inadvertently incurring the punitive penalties imposed by more draconian commercial confidentiality agreements. In the case of an external sponsor it is often good practice to stipulate the policy of the department with regard to publication - for instance commercial sponsors may be advised that "Should it be desired to publish any review of the project in an academic forum, or demonstrate the software or project to a wider audience, it is standard practice that sponsor concurrence will be sought." [8] Where the university is the sponsor of a confidential research project confidentiality agreements become much more highly problematic, and should be discouraged. As discussed above under "Student reuse of project work", the generic ownership and reuse of the underlying ideas, techniques and concepts developed during the project is a right that must remain with the students. The ethos of a university is based upon the liberal scientific ideal that the sharing of knowledge is to be encouraged as a public good. It should not therefore willingly enter into oppressive restraint of trade arrangements to bind its students.

It may be necessary to negotiate with the sponsor to mitigate the risk for students and modify a standard agreement normally geared to rather different circumstances. An example of such a communication with a particular external sponsor is provided in the Web site associated with this paper, in which a modification to the partner's standard confidentiality agreement to better reflect the nature of the relationship in the conduct of a capstone course was proposed. These terms were agreed to readily, and the company acknowledged that this was a new business relationship 
into which they were entering, and therefore different terms were warranted.

\section{Who should sign nondisclosure agreements?}

This will depend upon the agreements that are appropriate in the circumstances, and the key parties to those agreements. It is most relevant to those projects with an external or (more rarely) internal client/sponsor.

Normally the primary relationship will be between the students and the sponsor (who will have an authorized sponsor/signatory) and such agreements would be signed on an individual basis between the parties involved. The university may have appropriate legal procedures to accommodate significant secret developments, with certain delegated or authorized signatories to the relevant documents.

Note that the arrangements for nondisclosure may take quite some time to complete. It may be necessary to select the students who will be working with a sponsor earlier than the first week of the academic term. When arrangements are made early, there will be more time for legal departments to review and approve the special nondisclosure agreements that will be needed for academic projects.

\section{What policies should apply regarding students being paid for undertaking project work?}

- $\quad$ Permit the practice.

- Disallow the practice.

- Permit the practice in restricted circumstances, or with certain stipulations.

The laissez faire response is to simply permit students to earn money for working as a professional software developer for a commercial sponsor, which may assist them to remain a student. If the project sponsor is an internal research project they might be regarded as research assistants and be paid for their contribution to the project. For part-time students working in industry, if they can simultaneously meet the syllabus requirements of the university and the demands of their worksite by undertaking a significant project, then being paid is inherent in the situation. The benefit of such arrangements is that they allow students to complete their studies in a realistic context provided the project fits within the curriculum model and supervision processes afforded by the university.

Some universities and departments will have policies prohibiting payment for work that receives academic credit. If such rules exist, sponsors may make "gifts" to teams. Large cash gifts might prove extremely embarrassing to the instructor should they become public.
Should this experience be different from an unpaid internship? How is this experience different from an unpaid internship?

As discussed in relation to payment for students undertaking projects, an institution may choose to accept students being paid while undertaking their capstone course. For students in full time employment, undertaking a project which meets the academic requirements of the university can prove an option that offers mutual benefits. Some institutions may offer credit for the course post-hoc, by such mechanisms as recognition of prior learning upon presentation of the requisite proof of project activity and completion of such other academic deliverables (for instance a reflective report) that may be stipulated. In such a case the project work undertaken in industry may be very similar to a paid internship, but followed by a subsequent proving stage to gain academic credit.

One of the key considerations in capstone projects, internships, sandwich courses or cooperative education models is to clearly delineate the distinction between work experience and education. The distinction is often one that students find difficult to discern, particularly when the capstone has the goal of modeling professional practice. One of the key goals of any academic course of study is to have the student actively engage in a personal process of learning, and for a professionally oriented program of learning this should involve a solid element of reflection and critique. The requirements for submission of written documentation for assessment will normally differ for an academic program of study than for an industrial work experience activity. Likewise the requirements for a degree of professionalism in conduct of the development process and production of deliverables to a required standard may considerably exceed those of an amateur or slipshod work environment. Let us not forget that the increasing popularity of sharing "best practice" in commercial contexts arises precisely because there is so much bad practice out there. Our students should be prepared with state-of-the-art best practice, or with research informed techniques and insights that will lead them to improve upon existing industrial practices.

How should the conflict between sponsor needs and dictates and the professional responsibility to produce a soundly engineered and appropriate solution be resolved?

- The student(s) do exactly what the sponsor requests. 
- The student(s) do what they think best regardless of the sponsor requests.

- The students actively manage the relationship to achieve mutually acceptable outcomes.

- The instructor intervenes to resolve conflicts.

- Project management and process mechanisms are used to constrain the parties.

The process of developing software for a sponsor (whether internal, or external) involves a large range of variables and several, often conflicting, demands. Students will often fail to address these conflicting demands and instead of confronting issues will often simply acquiesce to the demands of their sponsor. The risks in this strategy are that students may produce a poorly engineered product based upon the sponsor's unduly narrow view of their own domain area or (often inappropriate) pet software product or design preferences. Students may be led to conduct their analysis or requirements engineering without the rigor needed to meet the "implied" as opposed to the stated or "specified" user requirements, or may allow an unacceptable degree of scope creep. The role of the instructor is to have mechanisms in place to monitor progress and quality in such cases, to intervene where necessary to safeguard the student from unrealistic commitments and to have means available to ask probing questions of the student to ensure that misconceptions are not carried forward into the later design and implementation phases.

In a case of severe scope creep, where the student(s) may lack the confidence to confront the sponsor and draw needed limits on the project, it may be necessary for the instructor to intervene and negotiate with the sponsor on the student(s) behalf. Even in a "taught" capstone course it will be common for the specification to have areas of ambiguity, deficiency or inconsistency, and students will frequently be expected to ask questions of the instructor as their sponsor to clarify the requirements before they continue.

Where students fail to see the need to consult their sponsor to gather necessary information or fail to confront the sponsor over differences and merrily forge ahead in their own way to produce a result to their own specification, a potential disaster is being created. The technocratic arrogance of the designer dictating to the sponsor is an attitude that should certainly not be reinforced in any capstone project experience. In a capstone model where professional capabilities are being developed, disabusing students of this conception is an important preparation for informed and sensitive professional practice. The instructor may explain the software development process as one of joint learning, where the sponsor or the intended end user has acknowledged expertise in his or her own problem domain, but not in that of software development and design, and the development process requires joint acknowledgement of expertise, so that a more active and balanced development process may result. The role of the software developer is not simply to focus on solving problems but to envision possibilities and enable opportunities. In fact the envisioning process is very similar to that used in corporate strategic planning and visioning processes [19]. In working with a sponsor it is important to work actively to create a shared vision informed by sponsor need and technology capabilities, within the overall project constraints. Thus, active management of this visioning process and maintaining good communication and shared expectations must be demanded of students to ensure a process that is respectful of the needs of the parties to the development.

Use of a sound project management process, including a project plan, a methodology with agreed deliverables, predefined review points and regular (say weekly) progress reporting to the instructor, is another useful mechanism to control these issues.

\section{Teams}

Team projects are often concerned with group development and the mix of interpersonal skills, as much as with technical outcomes and deliverables. The composition of the team and the way the group interacts is of key interest. Team members wonder if other members will do their part and if assessment will be fair. The success of a team is often dependent on a fair allocation of skills, interests and abilities, all dependent on interpersonal skills, teamwork skills, and the ability of the instructor to recognize and facilitate the process.

Students who have worked in teams during their earlier courses will experience the capstone course at a significantly different level than students who have not worked in teams before. Instructors will need to carefully consider previous experiences when determining team arrangements and procedures.

\section{How are teams formed?}

- Teams are self-selected, often based on affinity or project interest.

- The instructor forms teams, based on perception for success, student abilities, or random selection.

- The instructor selects the team leaders, who then form the team.

Teams should be formed so that they have a balance of skills, especially group dynamic skills. This may be different from a balance of academic skills. It may be more important to make sure that the 
background preparation of the group is addressed from a collective standpoint instead of mandating that each individual needs all prerequisite experience and coursework.

Allowing students to select their own teams has motivation implications. Instructor or team leader formation more actively reflects professional practice. It may be useful to have group sessions to facilitate team formation.

Some capstone project models may take the opportunity to combine teams across disciplines, to provide a broader student experience. For instance a multimedia development project may involve graphic artists, designers, programmers and subject matter experts combining for the duration of the project.

\section{How big should teams be?}

There does not seem to be a consensus on the optimal team size, other than it is desirable to attempt to have a balance in team sizes as much as possible. There is anecdotal evidence that there are penalties of scale when teams get above six or seven. Typical teams are comprised of 3-6 persons. Desired team size may be influenced by pedagogical desires, e.g., the two-person team experience may not be considered an adequate team experience.

When a team is permitted to consist of one or more individuals, care must be taken to prevent those students who always work alone from continuing to work alone throughout their education.

\section{Prerequisites and Preparation}

Final year computing students do not automatically have the skills necessary to be successful in the capstone course. The curriculum must provide the opportunity for students to gain the appropriate entry-level capabilities and disciplinary expertise to succeed in the course. Early foundations must be laid to ensure that the capstone course achieves its curricular goals.

\section{What kind of technical expertise is required?}

There may be difficulties if the capstone course has to communicate software engineering content in addition to other capstone course goals. Capstone courses that require a significant software development component will be a better experience for the students if they have previously completed a software engineering course. Furthermore, anecdotal evidence suggests that the greater the breadth of the student's technical expertise, the greater their willingness to work in unfamiliar areas of computing.

\section{What prior experiences are appropriate and relevant?}

- $\quad$ Experience working in teams.
- Experience with project management techniques.

- Experience with time management techniques.

- Experience evaluating, learning, and using new tools.

- Experience reading existing code.

- Experience making oral presentations.

- Experience doing technical/disciplinary writing.

- Experience using research methodologies.

- Experience doing reflective analysis (e.g. journal or log writing).

- Experience doing open-ended problem solving.

As a general rule, the capstone course is a bad place to introduce a multitude of new activities and concepts, although limited numbers of new activities and concepts are obviously necessary. Care must be taken that course activities actually support the goals of the course. In determining what prior experiences are appropriate, instructors should carefully consider the value of building on prior work - allowing both integration of concepts and perfection of performance.

Certain experiences will be useful and applicable regardless of where they occur in the curriculum. Oral presentation skills gained in another discipline easily transfer to presentations in computing. The same is not always true for writing skills; skill as an expository writer may not necessarily carry over into technical/disciplinary writing.

The earlier curriculum must support the capstone course. One possible model to build team experience is as follows. Course A (e.g., Software Engineering) requires team projects. The instructor selects the teams and meets frequently with the team to monitor and instruct on team dynamics. Course B, which has Course A as a prerequisite (e.g., Operating Systems) allows the students to select their own teams, but requires the same well-defined project components of each team. Finally, the capstone course, which requires Course $\mathrm{B}$, allows students to select both their own teams and their own projects.

If the curriculum prior to the capstone project provides few opportunities for students to exercise open-ended problem solving (i.e., they are always given a detailed description of what they are to do), then it is unreasonable to expect that they will be successful in an open-ended capstone project.

Instead of prerequisites the curriculum might choose to use the capabilities model [7]. In this model, in addition to a set of disciplinary skills called competencies, the curriculum enumerates a set of capabilities that need to be developed in the students. Capabilities can range from confidence with public 
speaking to coping with ambiguous and unexpected scenarios.

\section{Grading and Assessment}

Given the wide variation in types of possible projects and their deliverables, methods of grading and assessment will inherently vary. A number of models are possible, some emphasizing results, in which work products are the assessed items, others giving more emphasis on process, with dimensions such as effectiveness of team process being assessed. In addition to such considerations, the question of when work should be graded must be addressed, with some models requiring progressive assessment of work, and others conducting assessment at the completion of the project. The academic dimension of capstone project assessment is often addressed by means of a formal project report, involving a degree of critical reflection upon the project. Typically a combination of these approaches will be involved. For instance in one such model, an initial project proposal may be graded, as may conceptual, logical or physical design specifications, aspects of project management and teamwork, and a concluding reflective report.

Grading team products raises many issues when the environment emphasizes (or requires) individual work. The possible involvement of non-academic sponsors in assessment raises additional issues that must be resolved. Capstone courses that emphasize process over product will have their own assessment problems. Instructors must find ways to simultaneously calm student fears, involve appropriate individuals, protect students, support course goals, satisfy sponsors, and maintain appropriate standards. Instructors (or course coordinators) must also strive to obtain departmental agreement as to the criteria used for assessing capstone courses, particularly as it relates to the differences between process and product.

Instructors are often concerned about how to incorporate the evaluation of the technical difficulty of the project into the project grade. They are also concerned about whether grades should be given for the final result (holistic grading) versus giving grades for portions of the project (piecemeal grading). Whatever decisions are made, they should be carefully explained to all involved.

\section{What parties will have input into the} grading process?

In the context of the capstone course two elements seem to be particularly important: expectations and transparency. While grading guidelines for capstone courses may be less formal than prior courses, students in the course should have reasonable expectations and be able to make reasonable predictions of the grading results.

If other parties besides the instructor have input into grading, care must be taken to inform students of the process, the players, and the criteria used. As a general rule it is necessary to carefully determine what input is only advisory and ensure that those who are giving advice realize what they are doing.

Some departments

adopt departmental/committee grading for the capstone course. When this is done, it is appropriate for all members of the examination committee to be informed about all course activities and deliverables.

\section{Administration and Supervision}

Administering and supervising capstone projects involves several unique problems. These include workload issues for faculty, timing and scheduling of projects, approaches to supervision, matching teams with supervisors and projects, and consistency in supervision and managing project scope.

\section{Administrative Support}

Project-based work is a resource-hungry method of instruction. Supervision of even small projects requires a significant amount of time and attention from the instructor. As the project size and numbers scale up, the need to provide and coordinate instructors may become a departmental resource question. Questions dealing with adequacy of resources, consistency of workloads, and the quality of supervision take on an administrative instead of an academic nature.

\section{How is teaching credit given for capstone course instruction?}

- A formula of credit hour allocation.

- Normal teaching assignment for capstone course sections.

- Treated as an overload assignment.

- Treated as a normal duty of the instructor.

Giving no teaching credit for the course is a poor way of ensuring the quality and integrity of a capstone program. A department needs to have a formal method for granting teaching credit for the supervision of capstone projects. One common method is to award a fixed number of contact (or credit) hours for each student or student team supervised. Another option is to assign a course section for capstone projects as a regular teaching assignment. It is important that a method be used, and that it be used fairly and consistently. 


\section{Are there limits to the number of concurrent projects one instructor can manage?}

There is no one correct answer or even a standard list of options for this question. However, it is important that each institution and department have a plan for assigning instructors to capstone projects. The question is more critical when individual student projects are used and students are matched with an instructor. There needs to be a formula or policy for protecting the well-intentioned instructor from becoming overloaded with projects, and not being able to provide the necessary supervision to students. In addition, a policy needs to be used to ensure an equitable distribution of projects to instructors.

\section{What arrangements for capstone course instruction should be made?}

Supervision of capstone courses is not free, it is significant academic work, it must be counted towards load, and conscious acknowledgment of this time commitment should be provided for within departmental work allocation processes. It requires other resources than time, and they must also be made available. For this critical course, quality supervision requires that the right combination of knowledge, skills and abilities, academic, technical and managerial be marshaled, in order to maximize the chances of student and faculty success. The available options include the following:

- Everyone supervises.

- Use a selected small group of instructors.

- Supervision comes from outside the department.

- Graduate students serve as instructors.

- Industry sponsors serve as instructors.

In the situation where there are many students working on substantial, often individual, projects, it may be beneficial for all available instructors to share in the supervision of projects. This sharing of the workload will be considered fair only if everyone carries a reasonably equitable number of students or student teams. However, as more instructors are used, more coordination is required. Consistency among instructors and quality control become a major concern. If only a portion of the available pool of instructors supervise projects, there is the danger of a perceived unfair balance in the workload. An alternative is to have an equal rotating or sharing of supervision among the pool of instructors. In an attempt to maintain consistency among instructors, it may be beneficial to concentrate the project supervision responsibilities within a smaller group of faculty. A smaller subset of instructors can then concentrate on the skills necessary for facilitating successful projects, especially team-related skills, and work to maintain a collective view of the project goals. When the number of students increases beyond the point where unique individual and team projects can be accommodated, and the course by necessity [6] takes on a more structured form, it is desirable to have a tightly knit team of instructors with a common perspective to supervise the project consistently.

Whatever workload allocation model is used, a clearly defined description of workload expectations will need to be prepared.

Project supervision may be provided from staff in other departments in an effort to gain expertise and encourage interdisciplinary projects. If projects are shared among multiple disciplines, it may be helpful to have them assessed by both units. When using faculty from other departments, there needs to be clearly defined responsibilities and understanding of where the resources are coming from.

At many institutions, graduate students may provide the project supervision, under the coordination of regular faculty. This arrangement would be similar to using graduate assistants in laboratory projects. In this instance, it might be necessary or helpful for the instructor to provide lectures and instructions, and use the graduate students for one-on-one guidance. Benefits to this approach include the perception that another student is more approachable than the assessing instructor. However, as with adjunct or inexperienced instructors, graduate students may not be prepared for the needs of coordination of capstone courses. They may be tempted to become too involved with the students' work, providing more assistance than guidance.

When projects use outside industry partners, that sponsor may provide partial supervision responsibility, working with the academic staff. This gives the student a sense of credibility in the assessment process when using a real-world situation. It is paramount that adequate coordination be developed to ensure a common understanding of the expectations, requirements, and assessment process from the academic view.

\section{Where are projects scheduled in the program's curriculum?}

- In a student's final year as a single capstone experience.

- Anytime after all prerequisites have been met.

The most common practice for capstone projects is that they are a culminating experience. There are several models formalizing the process of scheduling capstone projects. If the capstone projects are all team-based and managed within the framework of a scheduled class with an instructor, it is much easier to place the capstone project within a program. If the capstone project is offered as an individual effort, 
then it becomes more critical to define an appropriate sequencing of prerequisite courses and the capstone project.

\section{When are projects scheduled into the student's program?}

- Registered at the start of the semester as part of the normal schedule.

- Registered at the end of the final prerequisite course, prior to the start of the capstone semester.

- Scheduled automatically as part of a predefined program.

Perhaps more important then where the capstone project course fits into the program's curriculum, is how students are prepared and advised in the process. Some programs have a formal process outlined whereby students are sequenced into a capstone experience. Other programs identify the capstone course similar to any other course in the curriculum, and the student simply registers when applicable. In programs that encourage or allow individual capstone projects, a process should be developed for students to arrange and receive approval for their project. Many departments require this to be done prior to the start of the semester in which the capstone project is begun. This addresses several concerns; first it aids in the scheduling and workload leveling of instructor assignments, and provides adequate time for arranging any external resources and schedules with sponsors.

\section{Supervision of projects}

Supervision is an important focus for teaching in the project setting. The instructor's role includes, but is not limited to, structuring, monitoring, managing, and assessing student work. An instructor's role may vary as the project progresses, and varies between students and/or student teams based on student needs at any given time. The instructor must balance managing the student team projects and the independence of student work. The involvement of the instructor begins at a higher level with direction at the start of a project, to students becoming largely self-dependent as they learn to rely on their own initiative and knowledge as the project progresses. The success and integrity of a project depends in large part on the role of the instructor. Getting a good fit in the instructor-student relationship can enhance the project experience for both the student and the instructor.

\section{How should project supervision by faculty be done?}

- Instructor as a monitor/observer commenting on the project work.
- Instructor directs the project, maintaining oversight and making decisions.

- Instructor as the project manager, but with less direct input in the decisions.

- Instructor acts as the sponsor, providing well-defined specifications and requirements.

- Instructor serves as the traditional teacher, imparting skills, and guiding team processes, as needed.

- Instructor acts as a mentor, i.e. using the project work to guide and teach.

- Instructor is the technical guru, i.e. resource manager, serving as a consultant.

When a supervisor serves as an adjunct observer, comments are intended as suggestions and possible solutions, not requirements that students must take. This may give students independence to show what they can do, without hindering progress when students are at an impasse. However, some students find it difficult to work without explicit details and will request more detailed instructions.

If an instructor takes a majority role directing the project, which includes maintaining oversight and making decisions, the instructor usually has an interest in the success of the project. This may more closely match an industry setting with the instructor providing experience and retaining responsibility. The danger is that the instructor overshadows the student's decision-making and learning process. As a result students often refrain from offering alternatives or making decisions. In addition, there might be a tendency for the instructor to become blind to problems due to the close involvement in the decision process.

The instructor as project manager can maintain a more remote role in the process of the project. In this environment, students make the detailed decisions with the instructor monitoring progress and offering broad guidance. This may be an appropriate role if the time schedule is critical and the product deliverable is important. If the instructor is the assessor of the project, students may become inhibited in exploring new alternatives.

Acting as the sponsor, the instructor provides specifications and requirements, but little or any technical guidance. Students take the role of consultants and developers, proposing solutions to meet those requirements. This simulates a real world practice in which students must elicit details as they implement their suggested strategy. It may be difficult for the instructor to maintain distance from the process, while at the same time not appearing too artificial.

Students understand the traditional studentteacher relationship. As a lecturer providing skills, teamwork guidance, technical skills, etc. as needed, the instructor works in parallel with the project, 
providing just-in-time information. Parallel development may be difficult however, for students to sift through lectures and material, determining what information is important for the project, as opposed to what is more general academic background.

Mentoring involves a close relationship between the instructor and individual needs of the student team or individual. This provides the appropriate skills and strategies for each case tailored to each student's learning process. This level of instructor involvement provides the maximum teaching environment, but is instructor-intensive, requiring significant time and insight. Mentors can find it hard to provide just the right amount of appropriate guidance, while letting the student learn and explore. It is also difficult to provide an even treatment between students based on individual receptiveness to mentoring, and reliance on guidance.

As the technical "guru" and resource, the instructor serves as a consultant, helping students with suggested techniques or technologies they may not have at their disposal. Providing technical help at the time it is most needed and relevant is an excellent way to teach those skills. This is only possible if the instructor has those abilities and experience, or if they are available. Assessing the projects become more difficult when students receive different amounts of help. This process, like mentoring, places a heavy time demand on the instructor.

\section{How are teams or students allocated to a supervisor?}

- Arbitrary allocation.

- Use existing student relationships.

- Students choose an instructor.

- Students propose, instructor chooses.

- Instructors invite.

- Team supervision with shared responsibilities.

The matchmaking process can be quite demanding and hard to implement in an evenhanded manner. A straightforward mechanism that treats all students the same also helps to even the workload. Using this process allocates staff based on where the need is. The weakness of this method is that it does not allow for matching individual needs. It also does not take advantage of special abilities of students and instructors. It spreads the load based on numbers, but may not fairly apportion the demand on instructors.

Many institutions already have existing relationships that can be maintained and relied on. For example, using existing student advisor assignments as the pairing process utilizes prior effort of developing relationships with instructors having insight into each students needs. As with an arbitrary allocation, this may not account for differences in the time demand on instructors based on individual demands of students, or technical skills of the instructors.

Allowing students to choose their instructor reduces the reason for student complaints about the supervision. The risk is that this can resemble a popularity contest resulting in an uneven balance of assignments. Failure to secure a desired instructor may have undesired consequences on the motivation of students, and hinder the subsequent instructor relationship.

Instructors inviting students who share mutual interests, an ability, or some other affinity, provides a chance to extend existing relationships and build on mutual interests. These invitations need to be coordinated among instructors to ensure that every student receives at least one, or perhaps only one, invitation. If students feel obliged to accept an invitation, it may have a less than desirable effect on student motivation.

An alternative allocation process is for instructors to pool their resources and share the supervision roles. Working in concert, instructors are able to use special knowledge or skills available. Ideally, instructors can do what they do best, and students receive the optimum level of support. Team supervision requires coordinating of the process resulting in overhead and perhaps even more work for instructors. The overlap in responsibilities however can be slightly offset by the limited focus of instructor involvement.

\section{How are student teams paired with projects?}

- Student or student team selects or proposes topic/project.

- $\quad$ One topic/project assigned to all students.

- Each student or student team assigned one sub-topic as part of the whole.

- Instructor assigns an individual topic to each student or student team.

The key issue of project allocation is who controls the choice of project, the student, or the instructor. The scale and scope of the projects impacts the number of projects that need to be generated, and how much of the project each student or student team is assigned.

One of the more simple mechanisms for handling project assignments is to assign only one topic to all student teams or individuals. This is simple and equitable. Students may learn from viewing the different approaches taken, and the problem of comparing projects with different technical difficulty levels is eliminated. Although solutions may differ, and group approaches may differ, there is value in comparing these different approaches.

If each student or student team takes on one aspect or subtopic of a larger project, students get to 
experience being part of a larger scope project. The approach requires more coordination on the part of the instructor to ensure that one student/team doesn't jeopardize the entire project.

If each student team is assigned an individual project, care must be given to ensure work of comparable complexity or scope. An advantage of this approach is that students tend to have a higher amount of ownership in their project, and students get to learn from the variety afforded by the different projects. This will, of course, require more effort on the part of the course instructor or coordinator to manage all of the different projects.

\section{How do you maintain consistency between multiple instructors?}

- Develop agreed-upon goals for project outcomes.

- Take the instructor differences into account on assessments.

- Invest in training and coordination of instructors.

- Use of peer marking or moderation techniques.

It is easy to assume multiple instructors have reached a consensus on the goals and objectives of a capstone course. To promote consistency between instructors it is important to create and adhere to a common set of objectives. As you recognize differences among instructors, it may become necessary to factor that into the student assessment process. In addition, it may be necessary to expend effort on training and coordination of instructors, or to institute quality assurance procedures, where peers may check mark one another's work and endeavor to reach a consensus on the final mark.

\section{Reflection, Analysis, and Review}

The capstone course will, among other things, have a maturing, confidence-building effect on the students. This transformation can be enhanced by an appropriate review and analysis of the process.

What devices can be employed to aid in student reflection, self-analysis and review?

- Interim reflective assignments and reports.

- Journal writing.

- Reflective essay required as a written deliverable at the project's end.

- Project completion interview.

- Presentation about their capstone experience to students entering their final year.

- Formal evaluations or performance reviews for team members.
Regardless of the devices used for reflection, there are certain issues that can aid in making the reflective activity beneficial. Students can be encouraged to reflect upon specific topics, such as the process, the product, the interaction within the team, interaction with the sponsor, the methodology used, the student's personal and professional development. Other issues that might help focus the student's reflection and self-analysis include:

- What initial processes were implemented? This might include: how the team was organized, how the problem was selected, or how the approach to the solution was determined.

- What conflict resolution took place? This includes how intra-team issues were resolved (if indeed they got resolved), team - instructor conflicts, and team -sponsor conflicts.

- Analysis of a critical incident(s) that occurred during the project.

- What role was the student most comfortable playing (e.g. peacemaker, leader, etc.)?

- What role was the student most uncomfortable playing?

- What experience was the most rewarding for the student?

- What contribution did the student consider most valuable?

- How were the student's contributions crucial to the success of the team?

\section{Should reflective work be assessed?}

Requiring reflective work is different from assessing it. The role of reflective work is to enable the student to become a more critical and self-aware professional, whose professional capabilities are continuously being improved. Assessment should not get in the way of the objective of reflective activities.

As a general guide, formal reflective reports should be clearly distinguished from diaries and personal logs. While the former may be assessed in a variety of ways, the latter may only receive a "was this task completed diligently and actively" assessment.

Using reflective work to assess the work of other team members is likely to destroy the effectiveness of the reflection. Assessment of the work of other team members should be done using more appropriate materials, e.g., logs, meeting minutes, weekly progress reports, and peer reviews.

\section{Information about the Web site}


This paper is not intended to be the only resource for instructors. The bibliography below references books, papers, and Web sites that contain valuable information. We are also in the process of creating our own web site of resources. Our site will contain samples of documents created and used by capstone course instructors. We invite readers of this paper to contribute to our repository their own examples of documents, courses, approaches, tools, techniques etc. so that it can become an active reference work facilitating the sharing of best practice. We hope our site will continue the work started with this paper, assisting instructors to supervise capstone projects successfully and enjoyably for themselves, their students and their sponsors.

We are in the process of establishing a fully maintained and supported host location for our web site. Our interim site can be reached at either http://www.cs.gvsu.edu/capstonecourses or http://www.cs.rose-hulman.edu/capstonecourses. Once the location is determined, these addresses will act as portals to the permanent site. Also note that there will be a link to our site from the ITiCSE conference historical Web site at http://www.cs.utexas.edu/users/csed/iticse/ : The link will be located with the other materials from the ITiCSE 2001 working groups.

\section{Bibliography and References}

1 Almstrum V., (2001), CS373 Software Engineering course description, Dept of Computer Sciences, University of Texas Austin, Retrieved June 25, 2001 from the World Wide Web:

http://www.cs.utexas.edu/users/almstrum/cs373/

2 Bagert D., \& Mengel S., (2001), Software Engineering Projects, Dept of Computer Science, Texas Tech University, Retrieved June 26, 2001 from the World Wide Web:

http://www.se.cs.ttu.edu/proj/

3 Bagert D., (2001), Forum for Advancing Software Engineering Education (FASE), Teaching Software Project Courses, Vol 11;6 (June), Dept of Computer Science, Texas Tech University, Retrieved June 26, 2001 from the World Wide Web:

http://www.cs.ttu.edu/FASE/

4 Bergin J., (2001), Java Course Student Tasks, CSIS Dept. Pace University, Retrieved June 25, 2001 from the World Wide Web: http://csis.pace.edu/ bergin/Java/StudentTasks.html

5 Bruegge B., (2001), Applied Software Engineering, Technische Universität München Institut für Informatik, Munich. Retrieved June 25, 2001 from the World Wide Web: http://wwwbruegge.informatik.tumuenchen.de/publications/
6 Chang E., Torabi T., \& Rahayu W., (1998), Issues and Solutions for Running a Full Year Software Engineering Project for Computing Majors, International Conference on Software Engineering: Education \& Practice, 26 - 29 January, Dunedin, New Zealand

7 Clear, T., (1997), Quality Control Expert System: A Project Review, The New Zealand Journal of Applied Computing and Information Technology, 1;1, pp. 49-62

8 Clear, T., (2001), Bachelor of Applied Science Software Development Project Sponsor's Guide, Auckland University of Technology, 1;1, pp. 1-10

9 Computer Science Undergraduate Projects (2001), Dept of Computer Science, Worcester Polytechnic Institute: Retrieved June 26, 2001 from the World Wide Web: http://www.cs.wpi.edu/Programs/mqps/

10 CSSE B Comp. (2001), The industrial experience project, Bachelor of Computing, Monash University Melbourne, Retrieved June 25, 2001 from the World Wide Web: http://www.csse.monash.edu.au/courses/bcomp/html/ industrial_experience.html

11 Dawson C., (2000), Computing Projects a Student's guide, Prentice Hall, Harlow

12 EPCOS - Effective Projectwork in Computer Science (2001), Computer Science Discipline Network (CSDN), Canterbury, University of Kent. Retrieved June 25, 2001 from the World Wide Web: http://www.cs.ukc.ac.uk/national/EPCOS/project_arc hive/

13 Fincher S., (Ed.) (1999), Computer Science Education, Special Issue on Project Work in Computer Science Education, 9:3, pp. 181 - 280

14 Fincher S., Petre M., Clark M., (Eds.), (2001), Computer ScienceProject Work Principles and pragmatics Springer-Verlag, London pp. 3 -267

15 Fincher, S., (2000), From Transfer To Transformation: Towards A Framework For Successful Dissemination Of Engineering Education, Proceedings of the 30 th ASEE/IEEE Frontiers in Education Conference, Kansas Missouri, IEEE, pp. F4-14-19, Retrieved June 25, 2001 from the World Wide Web: http://fie.engrng.pitt.edu/fie2000/papers/1269.pdf 16 Holcombe M., Stratton A., Fincher S., Griffiths G., (Eds.) (1998), Projects in the Computing Curriculum, Proceedings of the Project 98 Workshop, Sheffield, Springer-Verlag, London pp. 3 229

17 Jones A., (1999), Experience Of Profile Based Group Composition, Computer Science Education, 9:3 pp. 242-255

18 Lewis V., (1997), 53 Interesting Ways To Supervise Student Projects, Dissertations And Theses, Technical and Educational Services Bristol, pp. 1-171 
19 Lipton M., (1996), Demystifying the Development of an Organizational Vision, Sloan Management Review, Summer pp. 83 - 92

20 Luck M., (1999), Your Student Research Project, Gower Hampshire, pp. 1 - 186

21 Olesen H., Jensen J., (1999), Project Studies a late modern university reform? Roskilde University Press, pp. 7-305

22 Rutherfoord R., (2001) Using Personality Inventories To Help Form Teams For Software Engineering Class Projects, Proceedings of the $6^{\text {th }}$ Annual Conference on Innovation and Technology in Computer Science Education, pp. 73-76

23 UTS (2001), UTS Capstone Project Engineering Dept. University of Technology, Sydney. Retrieved June 25, 2001 from the World Wide

Web:

http://www.eng.edu.au/ deager/teaching.html 